\title{
Lithium and boron isotopes as tracers of hydrogeochemical processes in the hyperarid Salar de Atacama Basin, northern Chile.
}

F. Álvarez-Amado ${ }^{1,2^{*}}$, C. PoBlete-GonZÁleZ ${ }^{1}$, C. QuintANA-ORTIZ ${ }^{1}$, M. ROSALES ${ }^{1}$, L. GODFREY ${ }^{3}$

${ }^{1}$ Earth Science Department, Universidad de Concepción, Chile. (*correspondence:fernandaalvarez@udec.cl)

${ }^{2}$ Millennium Nucleus for Metal Tracing Along Subduction, FCFM, Universidad de Chile, Santiago, Chile.

${ }^{3}$ Department of Earth and Planetary Sciences, Rutgers University, U.S.A.

The Atacama region in northern Chile hosts the driest desert on Earth and is the world's second $\mathrm{Li}$ production province, where the occurrence of elevated Li concentration is restricted to brine deposits, such as the Salar de Atacama. The presence of $\mathrm{Li}$ in brine deposits is enigmatic. Most of the studies have been focused on the southern portion of the salar, which concentrates the higher $\mathrm{Li}$ concentrations. However, little is known about the hydrogeochemical processes controlling the Li distribution in the northern half of the salar. In this study, we analyze new geochemical and isotopic data $\left(\delta^{7} \mathrm{Li}, \delta^{11} \mathrm{~B}\right)$ from different $\mathrm{Li}$ reservoirs (natural waters, sediments and rocks) in the northern portion of the Salar de Atacama and draw comparisons with the processes occuring further south.

We analyzed $\delta^{7} \mathrm{Li}$ in different reservoirs. Natural waters $\delta^{7} \mathrm{Li}$ show a wide range of values (from -0.3 to 11.9 ). The lowest values are found to the north (geothermal fluids), whereas the highest are reported to the south of the Salar de Atacama (groundwaters and salt lakes). To the east, $\delta^{7} \mathrm{Li}$ presents a narrow range of values around $\sim 5.0$ in salt lakes. Ignimbrites show a wide range of $\delta^{7} \mathrm{Li}$ values (from -12.0 to 12.8), while sediments show a narrow interval (from -5.2 to 4.0).

These results suggest that at least two processes are controling the Li distibution in the different reservoirs. Lowtemperture wheatering dominates in surficial waters and groundwaters, whereas secondary phase precipitation seems to be a more important factor in salt lakes. The tectonic setting and proximity to the active arc are important as sources of solutes. On the other hand, $\delta^{11} \mathrm{~B}$ data indicate that some solutes are derived from sedimentary evaporites, unlike in the southern portion of the basin. Finally, we suggest that a high degree of water evaporation before reaching the salar is necessary to achieve the exceptionally high $\mathrm{Li}$ concentration in the Salar the Atacama basin. 